\title{
Correction to: The Characteristics of Romantic Partnerships in Women with Acquired Physical Disabilities: Intersecting and Compounded Vulnerabilities in a Community Sample in South Africa
}

\author{
Xanthe Hunt ${ }^{1}$ D $\cdot$ Amelia van der Merwe ${ }^{1} \cdot$ Wendy Xakayi $^{1} \cdot$ Stefani Du Toit ${ }^{1}$. \\ Laura Hartmann ${ }^{1}$. Alison Hamilton ${ }^{2,3}$
}

Published online: 26 August 2021

(c) Springer Science+Business Media, LLC, part of Springer Nature 2021

\section{Correction to: Sexuality and Disability https://doi.org/10.1007/s11195-021-09707-x}

The original version of this article unfortunately contained a mistake. The author name Laura Hartmann was incorrectly written as Laura Harmann. The author name has now been corrected.

The original article has been corrected.

Publisher's Note Springer Nature remains neutral with regard to jurisdictional claims in published maps and institutional affiliations.

The original article can be found online at https://doi.org/10.1007/s11195-021-09707-X.

Xanthe Hunt

xanthehuntwrites@gmail.com

1 Department of Global Health, Institute for Life Course Health Research, Faculty of Medicine and Health Sciences, Stellenbosch University, Francie van Zyl Drive, Bellville, South Africa

2 Department of Psychiatry and Biobehavioral Sciences, David Geffen School of Medicine, University of California Los Angeles, Los Angeles, CA, USA

3 VA Center for the Study of Healthcare Innovation, Implementation, \& Policy, VA Greater Los Angeles Healthcare System, Los Angeles, USA 